\title{
Socioeconomic differentials in mortality among older people
}

\section{A Bowling}

\section{Further investigation needed to find the most useful indicators of socioeconomic status in the elderly population}

$\mathrm{R}$ esearch in social epidemiology and medical sociology has consistently shown that people in lower socioeconomic status groups experience poorer health and live shorter lives than those in higher status groups. ${ }^{1}$ However, investigations of such differentials among people aged 65 and over is still comparatively rare. In this issue of the journal Huisman et al report on the results of their analyses of socioeconomic status (housing tenure, education) and mortality among older people. ${ }^{2}$ These were based on data from mortality registries linked with population census data from 11 European countries and regions. Institutionalised populations were not included.

Their results indicate that absolute and relative socioeconomic inequalities in mortality persisted into old age among men and women, and that relative socioeconomic inequalities in mortality were as great among older as middle aged people in some populations, although the age pattern of relative inequalities differed between populations by sex. However, an association between socioeconomic status and mortality was still present in the oldest age groups (90+). Their pooled data show that absolute socioeconomic mortality inequalities increased with age, while relative socioeconomic mortality inequalities generally decreased with age, although there were international variations in patterns. Overall, socioeconomic inequalities in relation to housing tenure were smaller than with education in the two oldest age groups. The authors conclude such inequalities are an important public health problem in Europe.

The issue of socioeconomic inequalities in morbidity, as well as mortality, has attracted a large number of investigators, but comparatively few have focused on elderly populations. By including the very old age groups, the study by Huisman makes a significant contribution to the literature on inequalities and mortality, and emphasises the importance of considering older people in public health policy and actions. It is a topic of increasing importance given the aging populations in developed countries, and increases in life expectancy, and given that most people who die and who are in poor health are aged over 60 .

\section{MEASURING SOCIOECONOMIC STATUS IN OLDER POPULATIONS}

The main problem facing investigators of socioeconomic inequalities is how best to measure socioeconomic status, particularly in older populations, while obtaining sufficient sensitivity to enable the identification of a manageable number of classifications, in hierarchical order, so that gradients in health inequalities can be investigated. ${ }^{3}$ Huisman et al used housing tenure and level of education as their indicators of socioeconomic status, on the basis mainly that the data were available for most populations studied. ${ }^{2}$ Even then, some data were missing: education was not available for Denmark and France for some of the older age groups; and missing data for education was large $(10 \%)$ in Denmark. Tenure was not available in France for those aged greater than 79 years.

Grundy and Holt analysed data from a national sample of adults in Britain with the aim of identifying which of seven indicators of socioeconomic status, used singly or combined, would be most useful in studies of health inequalities in older populations. ${ }^{3}$ They reported that the best pair of variables was education qualification or social class paired with a deprivation indicator. They argued that, for the purpose of studying health inequalities, indicators of socioeconomic status need to be sufficiently sensitive to permit differentiation between the relevant groups of people, and they should not themselves be a measure of health status in order to minimise problems of reverse causation in interpretations of the data. They illustrated the problems inherent in the most commonly used indicators of socioeconomic status in industrialised nations when used with older populations. Each indicator is context dependent, and thus the interpretation of international data requires the exercise of caution. In the case of occupation most people aged 65 and over are retired and for some, poor health in later years may result in early retirement or downward social mobility, or both. Questions on past employment history are required to reduce these problems of interpretation. Men and women also have quite different employment histories. Income is strongly associated with employment and therefore has similar problems as occupation as a measure of socioeconomic status, including those of reverse causation. It also adds additional complexities to data collection because of the large number of sensitive questions, which need to be asked about different sources of income (for example, benefits, pensions), which may also lower response rates.

One of the indicators used by Huisman et al was level of education. Grundy and Holt argued that problems with reverse causation are less serious with education, as educational attainment reflects early life achievements. ${ }^{3}$ Most members of older populations in Europe left school at the minimum age without any educational qualifications. Thus differentiation between groups is limited, permitting only the most advantaged group to be distinguished from others, and so there is insufficient differentiation between groups. Postschool qualifications, including apprenticeships, need to be included, although these have a greater chance of being influenced by health events in early adulthood. The problem of lack of differentiation is likely to be reduced in future as more educated populations move into older age groups.

Huisman et al also used housing tenure. This is a commonly used household based indicator of socioeconomic status, along with access to amenities such as central heating and a car. Such indicators have the advantage of applying to almost everyone living outside institutions, although they can be influenced by a range of factors. ${ }^{3}$ For example, lack of access to a car may reflect widowhood or disability, not income. Deteriorating health may prompt a number of very elderly people to move in with relatives, and housing tenure then reflects the socioeconomic status of the relatives, not the older person. Housing tenure, while the data can be comparatively easily collected, carries the disadvantage that most population members fall into the advantaged, higher status, group. Also, the exclusion of people living in institutions can be a more serious source of bias. ${ }^{23}$ Apart from being among the frailer members of society, they are more likely to be women and to have rented their former homes rather than owned them. 
Thus the exclusion of this group from the study by Huisman is likely to have the effect of minimising the reported socioeconomic differentials with mortality in older age. In addition, their finding that inequalities attenuated more among women suggests some bias. While the proportion of people who enter institutional care under the age of 85 is comparatively small, this increases considerably thereafter. The authors do admit, given that housing tenure was less sensitive indicator than education for the two oldest age groups, that this variable is a less useful indicator among the oldest-old.

Research on which indicator of socioeconomic status performs best as a predictor of health varies by nation. Grundy and Holt reported that the best pair of variables in studies of health inequalities in older adults in Britain was educational qualification or social class paired with a deprivation indicator. ${ }^{3}$ In contrast, von dem Knesebeck et al reported that income was the best predictor of three measures of health status among a sample of people aged 60 and over in Germany (excluding those living in institutions), whereas education, occupational prestige, financial assets (ownership of stocks, mutual funds or bonds, revenues from property), and home ownership were not consistently related to health. ${ }^{4}$ Their results were less clear in relation to the relative importance of these socioeconomic indicators in the United States. Such methodological problems may have deterred researchers in the past from investigating the links between socioeconomic status and mortality in older populations.

\section{EXPLANATORY MODELS}

In the study by Huisman et al, the age pattern of inequalities in mortality differed between countries, and the associations between inequalities in mortality and education and housing tenure displayed varying patterns. Some attenuation of risk might be attributable to cohort differences in social groupings. For example, in relation to housing tenure, owner occupation has become the norm in England and Wales, and thus middle aged tenants will differ in their social circumstances from older tenants.

However, even when taking methodological limitations and missing data into account, a range of causal pathways are likely to be operating. In their discussion, the authors tentatively focused on alcohol misuse and lifetime exposure to smoking, and variations with social class, sex, and age, referring to varying patterns in southern and northern Europe, as possible causes.
There are several, well known, explanatory frameworks that have been presented as possible explanations of socioeconomic inequalities in mortality in general populations. Materialist explanations hold that people with higher incomes can afford more nutritious food, live in better housing and in less polluted, safer environments, face less economic uncertainty, and have greater access to better quality health care. These factors may influence emotional wellbeing as well as health, functional limitations, and mortality risk. Relevant to this is neighbourhood level socioeconomic status that might influence health and mortality directly or indirectly through mechanisms such as available and accessible health services, information and education, healthy foods; environmental pollution; normative attitudes (for example, towards health, smoking); social capital and support. ${ }^{5}{ }^{6}$ There is a well established increased risk of adopting unhealthy lifestyles (in relation to smoking, alcohol intake, diet) among people in lower socioeconomic groups, perhaps partly attributable to underlying, adverse social conditions, which foster these practices. ${ }^{8}$ It seems logical to view these factors as influential across the life course, and thus a person's biological health becomes an outcome of their past social position. Long term interactions between a society's social structures (for example, opportunities for employment) and a person's life events (for example, employment, occupational mobility) theoretically produce patterns of cumulative advantage and disadvantage, producing further inequality in health between lower and higher status groups with increasing age. Psychosocial explanations also include the health effects of exposure to stressful situations over the life course, including low status and low autonomy (for example, at work). . Low status groups are arguably more likely to be exposed to stressful environments during their lifetime, and these, in turn, reduce individuals' reserve capacity for managing stress, thereby increasing vulnerability to negative emotions and cognitions with effects on health. ${ }^{10}$ In sum, socioeconomic inequalities in mortality in older age are likely to be a product of lifetime exposures to adverse social and neighbourhood circumstances and occupational exposures. ${ }^{11}$ These disadvantages are not necessarily compensated for by health service provision in each country, given detailed investigations of service receipt in parts of the UK that have shown that people aged 75 and over are less likely to receive indicated investigations. ${ }^{12}$ Moreover, people aged 65 and over worldwide have also been reported to adopt less critical attitudes towards their healthcare systems than younger people, ${ }^{13}$ suggesting that they may be less demanding. It is possible that different healthcare systems, and also social security systems, might account for at least some of the variations between countries reported by Huisman et al. Explanatory models, then, need to be multi-causal and to adopt a life course perspective. Absence of detailed, longitudinal data has hampered progress in this area, particularly in older populations, ${ }^{14}$ although there is some supportive evidence for the life course model. ${ }^{11} 15$

\section{IMPLICATIONS FOR PUBLIC HEALTH AND FUTURE RESEARCH}

Other investigators have noted a continuation of the social gradient of morbidity and mortality into older age, ${ }^{16}$ although a few have also reported a reduction, and speculated that this is possibly due to the operation of some selective survival of the fittest into old age or greater equalisation of health risks. ${ }^{17}$ The inconsistencies between investigations are likely to reflect the different measures of socioeconomic and health status used. The results of Huisman et al are consistent with the findings from studies that have investigated socioeconomic differentials in health status and disability among older, non-institutionalised populations, using a range of indicators of socioeconomic status (education, income, occupation, housing tenure, indicators of household resources and car ownership, neighbourhood deprivation). ${ }^{3}{ }^{18} 19$ Independent gender effects have also been reported, with women in early old age being at greater risk of disability than men. ${ }^{18}$

The study by Huisman et a provides further evidence on the extent of socioeconomic differentials in mortality among older people and also highlights an important public health problem. As the authors conclude, the reported variations in inequalities in mortality suggest that reducing these variations is achievable for elderly populations. The public health message, then, is that active measures need to be taken to reduce these differentials, as well as to ensure equity in access to health services in older age, given that inability to access services may be related to age, as well as to socioeconomic group. Action, of course, requires better information about causal pathways, and for investigators to be explicit about their preferred theories as these influence their choice of measures of socioeconomic status. Further exploration of the most useful indicators of socioeconomic status in older populations is required to facilitate further investigations of differentials in health status, health outcomes, and mortality. Information on 
causal pathways also needs more specific information about how socioeconomic factors are related to health and mortality over time. This necessitates the collection of more detailed longitudinal data on a wider range of topics in addition to indicators of socioeconomic status. These include health status, lifestyles, health and illness behaviour, emotions and cognitions, access to appropriate health care, exposures to stress (employment, family, and other histories), environment, social support, and social capital. The variations with sex in the study by Huisman et al also suggest that gender effects merit careful investigation in future research, as does any bias resulting from the exclusion of institutionalised populations.

\section{ACKNOWLEDGEMENTS}

I would like to thank Professor Emily Grundy for her valuable comments on the manuscript.

$J$ Epidemiol Community Health

2004;58:438-440.

doi: $10.1136 /$ jech.2003.017582

Correspondence to: Ann Bowling, Department of Primary Care and Population Sciences, University College London, Royal Free Campus, Rowland Hill Street, London NW3 2PF, UK; a.bowling@ucl.ac.uk

University College London is a member of the Medical Research Council Health Services
Research Collaboration (MRC HSRC), of which Bristol is the lead site.

\section{REFERENCES}

1 Machenbach JP, Kunst AE, Cavelaars AE, et al. Socioeconomic inequalities in morbidity and mortality in Western Europe. Lancet 1997;349: 1655-9.

2 Huisman $M$, Kunst $A E$, Andersen $O$, et al. Socioeconomic inequalities in mortality among elderly people in 11 European populations. $J$ Epidemiol Community Health 2004;58:468-75.

3 Grundy E, Holt $G$. The socioeconomic status of older adults: How should we measure it in studies of health inequalities? J Epidemiol Community Health 2001;55:895-904.

4 von dem Knesebeck O, Lüschen G Cockerham WC, et al. Socioeconomic status and health among the aged in the United States and Germany: a comparative cross-sectional study. Soc Sci Med 2003:57:1643-52.

5 Berkman LF, Glass T. Social integration, social networks, social support and health. In: Berkman LF, Kawachi I, eds. Social epidemiology. Oxford: Oxford University Press, 2000.

6 Pickett KE, Pearl M. Multilevel analyses of neighbourhood socioeconomic context and health outcomes: a critical review. J Epidemiol Community Health 2001;55:111-22.

7 Lynch JW, Kaplan GA, Cohen RD, et al. Do known risk factors explain the relation between socioeconomic status risk of all-cause mortality cardiovascular mortality and acute myocardial infarction? Am J Epidemiol 1996:144:934-42.

8 Jarvis MJ, Wardle J. Social patterning of individual health behaviours: the case of smoking In: Marmot M, Wilkinson RG, eds. Social determinants of health. Oxford: Oxford University Press, 1999

9 Marmot M, Theorell T, Siegrist J. Work and coronary heart disease. In: Stansfeld SA,
Marmot $M$, eds. Stress and the heart. London: BMJ Books, 2002

10 Gallo LC, Matthews KA. Understanding the association between socioeconomic status and physical health: do negative emotions play a role? Psychol Bull 2003;129:10-51.

11 Blane D. The life course, the social gradient, and health. In: Marmot M, Wilkinson RG, eds. Social determinants of health. Oxford: Oxford University Press, 1999

12 Bowling A, Bond M, McKee D, et al. Equity in access to cardiological investigations and interventions by age, gender and clinical indications. Heart 2001;85:680-6.

13 Bowling A. An inverse satisfaction law? Why don't older patients criticise health services? J Epidemiol Community Health 2002;56:482

14 O'Rand AM. The precious and the precocious: understanding cumulative disadvantage and cumulative advantage over the life course. Gerontologist 1996;36:230-8.

15 Breeze E, Sloggett A, Fletcher A. Socioeconomic and demographic predictors of mortality and institutional residence among middle aged and older people: results from the longitudinal study. J Epidemiol Community Health 1999.53.765-74.

16 Berkman C, Gurland BJ. The relationship among income, other socioeconomic indicators, and functional level in older persons. Journal of Aging and Health 1998;10:81-98.

17 House JS, Lepkowski JM, Kinney AM, et al. The social stratification of aging and health. $J$ Health Soc Behav 1994;35:213-34.

18 Adamson J, Hunt K, Ebrahim S. Socioeconomic position, occupational exposures, and gender: the relation with locomotor disability in early old age. J Epidemiol Community Health 2003;57:453-55.

19 Grundy $E$, Sloggett A. Health inequalities in the older population: the role of personal capital, social resources and socio-economic circumstances. Soc Sci Med 2003;56: 935-47.

\section{THE JECH GALLERY}

Influential women in occupational health Linda Rosenstock, MD, MPH-Expanding collaborations

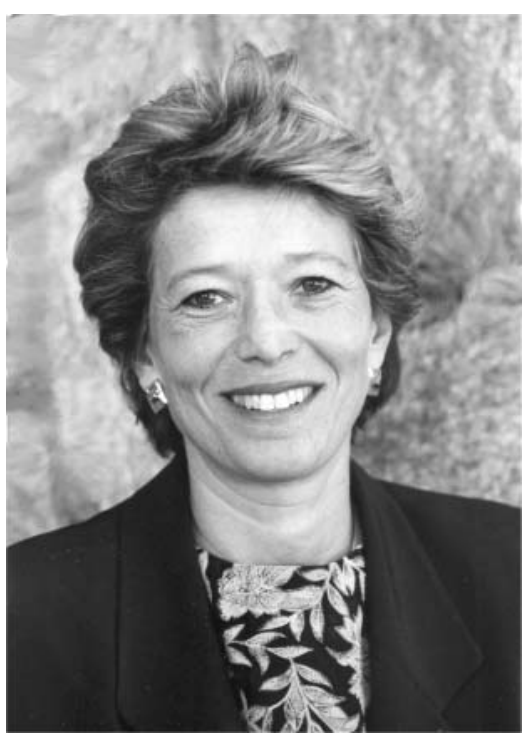

December 1950-, Country of birth: USA

D Linda Rosenstock views occupational medicine as inherently interdisciplinary, blurring the margins between individual healthcare delivery and public health. During her tenure as Director of NIOSH, Rosenstock doubled its annual appropriations-often credited to her partnership approach-and created the National Occupational Research Agenda (NORA), a framework for guiding occupational safety and health research, a collaboration with 500 external partners.

"Through government-labor-industry partnership, it became clear that changing mindsets, fostering flexibility, and making progress on common ground made the unimaginable possible."

Rosenstock acknowledges that rapid fundamental changes in the organisation of work have had an impact on occupational health and safety. Globalisation has led many companies to outsource, restructure, implement self managed teams, and/or streamline "just-in-time" production. These changes in the organisation of work have increased job stress related disorders. Over the past decade, disability due to stress related illness has doubled, implicating highly routine or fragmented work, time pressures, heavy cognitive demands, and reduced social support

Rosenstock brings her internationally recognised expertise and broad knowledge of public health to her current position as Dean of the UCLA School of Public Health.

\section{Clinical Communications Scientist, Pfizer Global Research and Development-Ann Arbor} Laboratories, Ann Arbor, MI, USA

I L Feitshans

Adjunct Faculty, Cornell University, School of Industrial and Labor Relations, Albany, NY, USA

Correspondence to: Deborah F Salerno, 2800 Plymouth Road, Ann Arbor, MI 48105, USA; deborah.salerno@pfizer.com 